\title{
"BREAKING DOWN BARRIERS": DEVELOPMENT OF AN ENGINEERING TECHNOLOGY TO ENGINEERING TRANSFER PATHWAY IN CANAda
}

\author{
Titilope Adebola ${ }^{a}$, Brian Frank ${ }^{a}$, Alexandra Downie ${ }^{a}$ and Hannah Smith ${ }^{a}$ \\ ${ }^{a}$ Queen's University \\ *titilope.adebola@queensu.ca
}

\begin{abstract}
College pathways significantly improve access to engineering degrees for marginalized or underrepresented students. Although several provinces in Canada have established pathways for students wishing to move from an engineering technology diploma to an engineering degree, such as Newfoundland and Labrador, Alberta, and British Columbia, no province-wide pathway in Ontario's higher education system exists. As a result, transfer students are faced with a myriad of challenges and limited transfer pathways due to the institution-specific and complex nature of transfer articulation agreements in Ontario.

This paper reports on the development of a provincewide diploma-to-degree engineering transfer pathway in Ontario. The proposed pathway program builds upon findings from a previous qualitative research study conducted by the co-authors which highlighted key factors necessary to develop future large-scale transfer pathways. The pathway was designed with the flexibility to incorporate extant institution specific pathways, while also providing a solid foundation for the development of a pilot multi-institutional bridge program. The challenges associated with creating a streamlined transfer pathway from engineering technology to engineering are myriad, and key outcomes from this project will continue to inform the development of possible approaches to a consistent, Ontario-wide engineering transfer program.
\end{abstract}

Keywords: Engineering transfer pathway, Engineering technology, Accreditation, Bridging program.

\section{INTRODUCTION}

Research has shown that students who enroll in college transfer programs predominantly come from underrepresented or traditionally disadvantaged groups [14]. College pathways to engineering programs could disproportionately improve access to engineering degrees for visible minorities and females, with some students relying on transfer as a pathway to a baccalaureate degree [5], [6]. These pathways provide an opportunity for students who did not meet the academic requirements in secondary school, did not have access to sufficient funding, or did not want to leave home [7]. Engineering programs would greatly benefit from increased diversity of the student population, which would result from increasing the transfer opportunities between engineering technology and engineering programs [2].

Several provinces in Canada have established pathways for students wishing to move from an engineering technology diploma to an engineering degree, such as Newfoundland and Labrador, Alberta, and British Columbia. There are also successful existing pathways in Ontario. However, the large variation in Ontario's higher education transfer policies, engineering and engineering technology syllabi, and course delivery and focus present a problem for the development of a large-scale transfer system in the engineering sector [8]. It is also generally the case, that transferring students receive minimal credit for courses taken. These students are often required to start an engineering degree from year one, and in many cases to repeat course material in order to meet accreditation requirements and/or learn the theoretical foundations which are part of an engineering degree program.

Consultations show a high industry demand for students with the kind of skillset developed through engineering technology/engineering transfer, as specified by institutions with already existent pathways. The project collected qualitative data to inform the proposers about risks and pitfalls in engineering transfer pathway development and implementation, as well as key considerations for successful engineering transfer. Some key points identified are the importance of full cooperation and collaboration of participating institutions, the need to meet incoming students at their current level of knowledge, and the large amount of bridging that may be necessary to successfully prepare students for entry into a new program.

As part of a larger project to develop an Ontario-wide network of transfer opportunities between engineering technology and engineering degree programs, this paper 
explores the development of a pilot pathway for students from participating engineering technology advanced diploma programs into year three of civil and mechanical engineering degree programs at Queen's University.

\section{CANADIAN ENGINEERING TRANSFER}

In a qualitative study performed by Smith et al. (2019), it was observed that existing pathways in Canada can be identified according to four main factors [9]: (1) timeline; (2) structure; (3) development; and (4) scale. The four factors will be discussed in more detail as well as the barriers to each factor.

\subsection{Timeline}

The timeline of the pathway refers to the year at which transfer students enter the degree granting institution [9]. Typically, transfer students are admitted into Years 2 or 3 of the receiving engineering degree programs. A common barrier to the timeline of existing pathways is curriculum gaps, as pathways for advanced diploma programs with significant gaps in the curriculum are more likely to have to enter the first or second year of the engineering program. Also, misalignment between graduation schedules for advanced diploma programs and entry intake for engineering degree programs could potentially increase the timeline to engineering degree completion.

\subsection{Structure}

It is current practice to assess transfer on a case-by-case basis for a student wishing to transfer from an engineering technology program to an engineering degree program at a receiving institution in Ontario where no articulation or transfer agreement exists. It is also common practice for pathways to include "bridging/transitory programs" consisting of a set of courses taken over a specified period (i.e. an academic term) to bridge the gaps in the curriculum. Some common barriers to the structure of existing pathways include; minimum accreditation requirement, balancing student workload and institution/disciplinespecific nature preventing flexibility to include multiple programs.

\subsection{Development}

Pathway development is typically institution specific, and in most cases discipline specific. Due to the streamlined nature of transferred pathways and variations across institutions and disciplines, in some cases, engineering programs are built to accommodate the needs of transfer students, which makes the first year or two of engineering somewhat similar to a technology program, and typically less focused on mathematics and science. In some other cases, pathway programs are developed with entry requirements equivalent to an advanced diploma degree but which are not accredited by the Canadian Engineering Accreditation Board (CEAB). An example of this is a Bachelor of Technology (BTech) degree rather than an accredited engineering degree (e.g. BTech programs at McMaster and Queen's). In other cases, as in the situation in this paper, a pathway must be developed between existing programs that were not designed to be complementary. A common barrier to efficient transfer in this case is heavy emphasis on mathematics and science in the first two years of engineering programs.

\subsection{Scale}

It is common practice for institutions to adopt a caseby-case articulation agreement model for transfer pathways. As a result, the scale of transfer pathways varies across Canada. However, this approach could limit the development of a large-scale transfer pathway since the pathways are locally optimized to the individual programs. Frequently the number of students in these pathways is small so economies of scale present a financial challenge to delivery.

\section{PROPOSED TRANSFER PATHWAY}

The proposed pathways so far were developed for students from participating engineering technology advanced diploma programs transferring into year three of civil and mechanical engineering degree programs, ideally involving 3 years in the engineering technology program followed by 2 years in an engineering program. Although the long-term goal is to develop a provincial network of transfer opportunities between engineering technology and engineering degree programs, it was more feasible and practical to limit the scale of the pilot project to two disciplines and one degree granting institution, Queen's University. To be successful, such a pathway must address the challenge of providing additional courses in a timely manner while maintaining a manageable workload and ensuring that program accreditation requirements are met.

\subsection{Design Criteria}

The design criteria builds upon outcomes of a qualitative research study by Smith et al. (2019), where semi-structured interviews with 15 institutions having existing or attempted transfer pathways in Canada were conducted. Student interviews and discussions with instructors from technology programs revealed that in Ontario, student motivation for vertical transfer into engineering was centered on career growth, eligibility for professional engineer (P.Eng) designation and academic improvement [7]. Given these factors, some of the key criteria identified in creating the pathway include:

- Minimizing requirement to track P.Eng. status of instructors in technology programs. In a multi- 
institutional system this can be a challenge to maintain, and curriculum analysis is showing that there are sufficient opportunities to involve P.Eng. instructors in the bridge and engineering degree program to satisfy $\mathrm{CEAB}$ requirements.

- Ensuring $50 \%$ of AUs come from receiving institution, and all $\mathrm{CEAB}$ AU category requirements are met

- Identify the common gaps between the majority of sending and receiving institutions, minimizing the number of courses/modules that need to be taken by a small number of students

- Ensure the bridge program is specifically designed to address the needs of students coming from engineering technology programs (i.e. primarily focusing on application of fundamental science to modeling and analysis)

- Provide flexibility in speed through which students can move through the pathway; ideally allow for a $3+2$ year progression for students with strong academic background, and longer for those who need additional time and support

- Provide coordinated student support between sending, receiving, and Bridge institutions.

\subsection{Pathway Structure}

This pathway program builds upon four previous ONCAT funded projects (\#2015-29, \#2016-11, \#2018-06 and \#P1912) where learning outcomes, course materials, and course descriptions were used to compare engineering and engineering technology programs in Ontario and investigate existing engineering technology/engineering transfer pathways and programs across Canada [10]. In an attempt to reduce necessary course load in the bridge, initial curriculum overlap and gaps were identified for a range of Ontario institutions, which gave an idea of where bridging courses would be focused. In the case of significant gaps, the pathway was designed to enable students begin some preparatory course work either online or in person at an institution within close proximity to the sending institution. Students could also fill courses as necessary in year three or four at the degree granting institution.

A one-term bridge was not found to be feasible to fill the necessary gaps required for a multi-institutional pathway, due to accreditation requirements and differences between technology programs and the first two years of most engineering programs. This led to the development of a three-phase transfer pathway model:

1. Phase 1: While students are enrolled in their advanced diploma program, they would take a small number of additional courses that are core to the engineering degree. Courses could be delivered online or at a local institution offering engineering degrees, and serve to fill critical gaps in first year knowledge needed for courses in the bridge and upper-years. This will likely involve introductory programming and calculus.

2. Phase 2: This section will be completed at a designated Bridge Institution prior to entering the receiving institution. Courses will focus on common knowledge gaps to allow the student to enter the receiving institution with background mostly equivalent to a student completing their $2^{\text {nd }}$ year of engineering. This phase will include some elements of engineering design and practice, science, mathematics, and discipline-specific engineering science.

3. Phase 3: This section will be completed at the receiving degree granting institution. Students would be completing the typical $3^{\text {rd }}$ and $4^{\text {th }}$-years of their engineering degree, with additional courses to meet CEAB requirements.

The proposed pathway was designed with the flexibility to incorporate extant institution specific pathways, while also providing a solid foundation for development of a pilot multi-institutional bridge program.

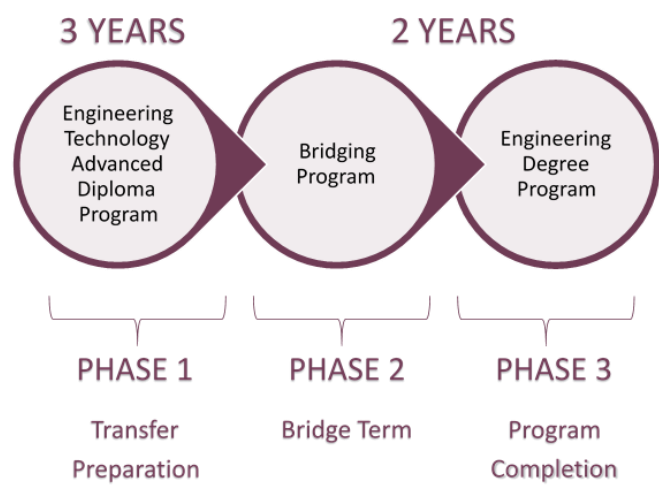

Fig. 1. Proposed Three-phase transfer pathway model.

\subsection{Development of Student Supports}

Student interviews and discussions with instructors from technology programs identified that student support will be critical to success in transferring. The time spent on fundamental mathematics and science in Ontario's technology programs varies considerably between institution, and some students may need significant support in engineering calculus, algebra, physics, and chemistry. Academic, time management, and wellness support needs to be built into phase 1 and 2 of the pathway. This could include flexibility in completion time, remedial instruction, 
developing a supportive community among the cohort of students in the pathway, and support counsellors.

\subsection{Student Benefits}

Students will benefit directly from this pathway, as it will increase the viability of transfer between engineering technology/engineering programs in Ontario. Student interviews identified that transfer students were more academically prepared for university, developed diverse skillset and benefited from a reduced time-to-degree completion [7]. For graduates of technology-toengineering transfer programs, faster career advancement in comparison to colleagues with only an engineering degree was reported [7]. The proposed transfer pathways will increase mobility and ease of access for underrepresented learners, with focus on partnerships and support for Indigenous students entering engineering via engineering technology programs. Additionally, students will obtain both a degree in engineering and a diploma in engineering technology, and the option to register as an Engineer-in-Training (EIT) with Professional Engineers Ontario, to complete the requirements for designation as a Professional Engineer (P.Eng).

\subsection{Challenges}

The challenges associated with creating a streamlined transfer pathway from engineering technology to engineering are myriad, and as we progress towards a more defined model, there will no doubt be new issues that emerge. Some identified challenges include;

Curriculum Gaps: For technology institutions that include relatively little mathematics and science, a 3+2 multiinstitutional approach would not be feasible due to the time it would take for students to complete the additional courses needed to meet accreditation requirements. In such cases, it may necessary to for the participating engineering technology program to consider either curriculum reform (i.e. changes or additions to courses), or plan for additional time to progress through the pathway.

Course Scheduling: Scheduling complications may be an issue for the three-phase pathway students due to nonstandard course combinations.

Workload: Students entering the pathway will be faced with a workload that is significantly heavier than that of their college classmates, which may impact their technology courses. The workload of the Bridging program needs to be large enough to obtain the requisite AUs for accreditation without overworking the students.

\section{CONCLUSION}

There is great potential for a province-wide diplomato-degree transfer pathway to improve access to engineering education for students from underrepresented communities. However, the success and longevity of such a program is dependent on several key factors. Barriers affecting the timeline, structure, development and scale of such a program must be overcome to ensure that the pathway is student-centered. Sustained collaboration and communication between partnering institutions will also be important.

\section{Acknowledgements}

We would like to thank the faculty and staff at St. Lawrence College, Mohawk College, Cambrian College, Conestoga College, Seneca College and Centennial College for their contributions and participation. We are also grateful to the Ontario Council for Transfer and Articulation (ONCAT) for providing the funds to support this program.

\section{References}

[1] D. Trick, "Transfer Arrangements and Undergraduate Education: Ontario in a National and International Context. Higher Education Quality Council of Ontario,” 2013.

[2] A. M. Ogilvie, "A review of the literature on transfer student pathways to engineering degrees," in ASEE Annual Conference and Exposition, Conference Proceedings, (Indianapolis, IN, June 15-18 2014), 2014, pp.1-14.

[3] A. M. Ogilvie, D. B. Knight, A. A. Fuentes, M. Borrego, P. A. Nava, and V. E. Taylor, "Transfer student pathways to engineering degrees: A multiinstitutional study based in Texas," in Proceedings - Frontiers in Education Conference, FIE, 2015, pp. 1-5, doi: 10.1109/FIE.2015.7344391.

[4] J. Perez, S. Y. Yoon, T. Reed, and C. D. Lawley, "Enriching the diversity of the engineering workforce: Addressing missed opportunities to support student transition from a two-to a four-year institution," in ASEE Annual Conference and Exposition, Conference Proceedings, (El Paso, TX, USA Oct 21-24 2016), 2016, pp. 1-11, doi: 10.18260/p.26721.

[5] L. Lattuca, P. Terenzini, H. K. Ro, and D. Knight, "America's Overlooked Engineers: Community Colleges and Diversity in Engineering Education," Jun. 2014.

[6] M. D. Sullivan, C. C. De Cohen, M. J. Barna, M. K. Orr, R. A. Long, and M. W. Ohland, "Understanding engineering transfer students: Demographic characteristics and educational outcomes," Proc. - Front. Educ. Conf. FIE, pp. 1- 
6, 2012, doi: 10.1109/FIE.2012.6462442.

[7] H. Smith and B. Frank, "Investigating Student Experiences of Engineering Technology to Engineering Transfer in Ontario," in 2020 Canadian Engineering Education Association (CEEA-ACEG20) Conference, 2020.

[8] S. Zakani, B. Frank, R. Turner, and J. Kaupp, "Framework for transferability between engineering and technology programs: Project 2015-29," Toronto, 2016.

[9] H. Smith, N. Mulligan, B. Frank, A. Downie, and R. Gholami, "'Meet Them Where They're At': Gathering Institutional Perspectives on Engineering Technology to Engineering Transfer in Canada," in 2019 Canadian Engineering Education Association (CEEA-ACEG19) Conference, 2019, pp. 27-37.

[10] H. Smith, M. R. Gholami, A. Downie, B. Frank, R. Turner, and N. Mulligan, "Bidirectional Transfer Pathway for Ontario's Engineering and Technology Programs Final Report,” 2019. 